Artigo Original

Original Article

Giorvan Ânderson dos Santos Alves ${ }^{1}$ Julyane Feitoza Coêlho ${ }^{2}$ Márcio Martins Leitão ${ }^{3}$ (1)

Descritores

Doença de Alzheimer

Linguagem

Fonoaudiologia

Psicolinguística

Semântica

Keywords

Alzheimer's Disease

Language

Speech Therapy

Psycholinguistics

Semantics

Endereço para correspondência: Giorvan Ânderson dos Santos Alves Departamento de Fonoaudiologia, Universidade Federal da Paraíba UFPB

Cidade Universitária, s/n, Conj. Pres. Castelo Branco III, João Pessoa (PB), Brasil, CEP: 58051-900.

E-mail: anderson_ufpb@yahoo.com.br

Recebido em: Abril 28, 2020

\section{Processamento correferencial em idosos com e sem doença de Alzheimer}

\author{
Coreferential processing in elderly with and \\ without Alzheimer's disease
}

\begin{abstract}
RESUMO
Objetivo: Comparar o processamento correferencial, em idosos com e sem a Doença de Alzheimer, no Português Brasileiro. Método: Participaram 12 idosos sem Alzheimer (ISA), e 06 idosos com a Doença de Alzheimer (IDA). O Mini-Exame do Estado Mental foi utilizado para triagem cognitiva dos participantes. Dois experimentos foram realizados utilizando a técnica de leitura automonitorada para analisar o processamento da correferência, cada um contendo oito frases experimentais e 24 frases distratoras, um deles utilizou pronomes e nomes repetidos, já o outro utilizou hipônimos e hiperônimos. Após a leitura, foram realizadas perguntas relacionadas ao conteúdo das frases. A principal variável de interesse foi o tempo de leitura aferido após a apresentação das retomadas anafóricas. Resultados: No primeiro experimento, foram encontrados resultados estatisticamente significantes, no grupo ISA os pronomes foram processados mais rapidamente do que nomes repetidos, e no grupo IDA, os voluntários foram mais rápidos na retomada do nome repetido. No segundo experimento, os resultados demonstraram que o grupo ISA apresentou preferência, na retomada anafórica, pelos hiperônimos, já o grupo IDA não apresentou diferenças significativas entre as condições. Conclusão: Os idosos sem patologia processaram mais rapidamente pronomes e hiperônimos, quando comparados a retomadas com nomes repetidos e hipônimos, respectivamente, pela menor quantidade de traços semânticos necessários para identificar os antecedentes naquelas condições, assim como pela proeminência sintática e discursiva. Nos idosos com DA, os nomes foram lidos mais prontamente que pronomes, e não houve diferença no processamento anafórico envolvendo hipônimos e hiperônimos, podendo decorrer do comprometimento na memória de trabalho.
\end{abstract}

Trabalho realizado na Universidade Federal da Paraíba - UFPB - João Pessoa (PB), Brasil.

${ }^{1}$ Departamento de Fonoaudiologia, Universidade Federal da Paraíba - UFPB - João Pessoa (PB), Brasil.

${ }^{2}$ Programa de Pós-graduação em Linguística, Universidade Federal da Paraíba - UFPB - João Pessoa (PB), Brasil.

${ }^{3}$ Departamento de Línguas Clássicas e Vernáculas, Universidade Federal da Paraíba - UFPB - João Pessoa (PB), Brasil.

Fonte de financiamento: nada a declarar.

Conflito de interesses: nada a declarar. 


\section{INTRODUÇÃO}

A Doença de Alzheimer (DA) é uma patologia neurodegenerativa que atualmente representa a forma mais comum de demência em idosos e caracteriza-se como uma doença multifatorial complexa, com comprometimentos que envolvem cognição, memória e o comportamento. O diagnóstico clínico da síndrome demencial considera o histórico do paciente, testes neuropsicológicos, exames de imagem e avaliação longitudinal dos sintomas, utilizando-se do fenótipo clínico combinado com informações de biomarcadores. Existem desafios associados ao processo de diagnóstico e ao desenvolvimento de tratamentos eficazes para reverter o quadro clínico ${ }^{(1)}$.

Os idosos com DA podem apresentar diversas alterações cognitivas, como os déficits na memória episódica, memória de trabalho e função executiva, sendo que, esses déficits cognitivos começam precocemente durante o período de Comprometimento Cognitivo Leve, que representa o estágio entre o declínio cognitivo esperado no envelhecimento normal e o declínio mais grave observado na DA, e parecem ser um sinal de progressão para a doença $a^{(2)}$.

Os déficits de linguagem geralmente se tornam visíveis desde o estágio inicial da doença e os seus diferentes estágios exibem padrões específicos de dificuldades linguísticas, afetando de modo distinto os diversos domínios. As deficiências nas funções lexicais, semânticas e pragmáticas da linguagem estão tipicamente presentes na DA leve, uma vez que dependem mais da cognição. Já os domínios articulatórios e sintáticos da produção da linguagem permanecem intactos até os estágios finais da doença. No que se refere à sintaxe, os prejuízos envolvem a redução da complexidade sintática e a presença de agramatismos. Nesses indivíduos, as funções de linguagem e memória estão intimamente relacionadas, pois o funcionamento linguístico requer funções de memória, de modo que as dificuldades na produção da fala, na compreensão e nas funções de memória se sobrepõem ${ }^{(3)}$.

Um importante aspecto a ser considerado nesses indivíduos é o processamento linguístico, o mesmo pode ser entendido como o processo de compreender e produzir linguagem verbal em nosso cotidiano, que na sua complexidade requer um conjunto de procedimentos mentais. Independentemente de a via ser oral ou escrita, são as habilidades cognitivas relacionadas à linguagem que se encontram em funcionamento ${ }^{(4)}$.

O processamento anafórico envolve a utilização de anáforas, entendidas como expressões linguísticas cujo significado depende de uma parte anterior da sentença ou discurso, denominada antecedente. Por comumente fazerem referência ao mesmo elemento do enunciado, anáfora e antecedente são consideradas correferenciais ${ }^{(4)}$. A referência a um elemento já mencionado anteriormente na sentença pode ser estabelecida através do uso de retomadas anafóricas, ou seja, expressões que estabelecem correferência com seu antecedente que já foi previamente introduzido. Por isso, a proeminência discursiva e a memória de trabalho afetam o processamento de expressões anafóricas. As retomadas anafóricas requerem um processo de comparação para identificar o antecedente, um processo bastante sensível à relevância dos diferentes elementos presentes na sentença. O efeito da proeminência discursiva na resolução da referência é universalmente refletido na linguagem humana pela distribuição das formas anafóricas de acordo com a saliência de seus referentes ${ }^{(5)}$.

Uma das questões centrais no que diz respeito ao processamento anafórico diz respeito às várias formas de retomadas anafóricas utilizadas nas línguas e a possibilidade de algumas dessas formas serem mais eficientes do que outras em termos de processamento e custo de memória de trabalho. As retomadas podem, por exemplo, se apresentar como pronomes, nomes repetidos, categorias vazias, ou mesmo por meio de Sintagmas Nominais (SNs) que podem estabelecer uma retomada a partir de uma relação de hiperonímia ou hiponímia com seu antecedente. Nessa perspectiva, duas concepções teóricas trazem importantes contribuições para essa discussão: A Teoria da Centralização ${ }^{(6)}$ e a Hipótese da Carga Informacional ${ }^{(7)}$.

A Teoria da Centralização tem como um de seus princípios a eficiência dos pronomes no estabelecimento da correferência com entidades estruturalmente e discursivamente mais proeminentes ${ }^{(6)}$, e a Hipótese da Carga Informacional também propõe que as retomadas anafóricas são processadas e lidas mais rapidamente quando seu antecedente é proeminente no discurso (na posição de sujeito).

A Hipótese da Carga Informacional, pragmaticamente proposta para dar conta da análise do uso de tipos diferentes de retomada anafórica, relaciona o custo do processamento de uma retomada anafórica com a medida da carga informacional, medida essa que é associada com a distância semântica entre o antecedente e a retomada, além de levar em conta a proeminência sintática. De modo que, quanto mais proeminente o antecedente, menos seria adequada funcionalmente a utilização de um nome repetido e, por isso, optar-se-ia por um pronome que teria assim uma carga informacional menor do que os nomes repetidos, nesse contexto ${ }^{(7)}$.

Estudos têm mostrado que, considerando adultos sem patologias $^{(8-11)}$ e crianças ${ }^{(12)}$, pronomes são mais eficientes do que nomes repetidos em várias línguas e que hiperônimos são mais eficientes do que hipônimos ${ }^{(5)} \mathrm{em}$ indivíduos sem patologias, em determinadas circunstâncias sintático-discursivas. O processamento de hiperônimos também é facilitado em relação ao de hipônimos no português brasileiro em adultos saudáveis ${ }^{(13)}$. E há resultados divergentes na Penalidade do Nome Repetido em Português Brasileiro, em pesquisas com adultos sem patologias, alguns estudos têm encontrado sistematicamente a ocorrência do fenômeno, com pronomes sendo processados mais rapidamente do que nomes repetidos, tanto na posição de sujeito, quanto na posição de objeto ${ }^{(3,13-16)}$, entretanto há estudos que não têm encontrado tais diferenças ${ }^{(17-20)}$.

Sobre essa divergência, estudo verificou que dependendo de fatores metodológicos e linguísticos, como a forma de aferição do tempo de leitura, se apenas da retomada ou da sentença toda, e se há um ou mais de um potencial antecedente humano nos estímulos testados, se pode encontrar ou não a Penalidade do Nome Repetido, ou seja, o fenômeno parece ser multifatorial e de acordo com o arranjo entre os fatores controlados e os estímulos utilizados, os resultados vão em uma ou outra direção ${ }^{(21)}$. Diante disso, na presente pesquisa, foi seguida uma perspectiva entre 
estímulos e fatores anteriormente $\operatorname{adotada}^{(3,15)}$, assim garantiuse o controle dos fatores que têm encontrado os resultados na direção da presença da Penalidade do Nome Repetido em adultos sem nenhum tipo de transtorno ou déficit linguístico.

A pouca produção científica em processamento correferencial em indivíduos com alterações neurológicas foi um dos aspectos motivadores para pesquisar a temática nos idosos com Alzheimer. Partindo dessa motivação, tomou-se como base de partida para o estudo em processamento correferencial, a pesquisa no Inglês ${ }^{(5,7)}$, que teve grupo de investigação semelhante, idosos com Doença de Alzheimer. Esses estudos, fazendo uso de uma metodologia de nomeação cross-modal-procedimento que utiliza combinação de mais de uma modalidade sensorial - demostraram que, embora a fala de pacientes com Alzheimer seja caracterizada pelo uso frequente e inadequado de pronomes, o uso de nomes repetidos torna-se mais funcional pelo déficit na memória de trabalho que influencia o processamento correferencial na leitura. Os seus resultados experimentais em pacientes com DA, comprovaram que esses sujeitos tinham mais problemas no estabelecimento da correferência quando as retomadas anafóricas eram feitas com pronomes do que quando eram feitas com nomes repetidos.

Nesse sentido, o estudo do processamento anafórico em pacientes com DA pode permitir avanços na investigação de que componentes estão prejudicados em termos linguísticos e que relação os mesmos estabelecem com os aspectos cognitivos. Diante disso, este estudo tem por objetivo analisar e comparar o processamento da linguagem, por meio da correferência, em idosos com e sem a Doença de Alzheimer, no Português Brasileiro.

\section{MÉTODO}

A presente pesquisa se classifica como quantitativa, experimental e transversal. Esta investigação buscou a realização de experimentos psicolinguísticos para obter evidências empíricas a partir de técnicas experimentais, focalizando o processamento da correferência na leitura de sentenças coordenadas. O estudo foi realizado em uma Instituição de Longa Permanência e no Laboratório de Processamento Linguístico, vinculado ao Programa de Pós-Graduação em Linguística, da Universidade Federal da Paraíba, ambos localizados no município de João Pessoa-PB.

\section{Amostra}

Para serem inclusos na pesquisa, os voluntários deveriam apresentar idade cronológica de 60 anos ou mais, um grau de escolaridade de, no mínimo, o ensino fundamental completo, pela necessidade dos participantes terem leitura fluente das frases experimentais e distratoras; não ser ou não ter sido acometido por nenhuma doença neurológica, motora ou psiquiátrica, que pudesse interferir nos resultados, uma vez que a pesquisa busca a análise com idosos saudáveis (ISA) e com DA (IDA); e não ser acometido por deficiência visual e/ou auditiva, que viesse a interferir na compreensão da execução e/ou na leitura das frases experimentais. Além disso, ao ser submetido ao Mini-Exame do Estado Mental (MEEM) ${ }^{(22)}$, como teste de rastreio cognitivo - considerando os pontos de corte de acordo com o nível de escolaridade $^{(23)}$ - apresentar um escore de bom desempenho cognitivo no grupo ISA e de declínio cognitivo leve no grupo IDA, o que os torna capazes de compreender e participar das tarefas experimentais. No caso do grupo IDA, os voluntários também deveriam apresentar em seu prontuário institucional o diagnóstico de Doença de Alzheimer em sua fase inicial.

A média dos escores do MEEM foi de 26,5 no grupo ISA e 18,0 no grupo IDA. A idade média dos participantes foi de 72,8 anos. Considerando os níveis de escolaridade, a maioria dos participantes concluiu o ensino médio $(44,44 \%)$ e os demais concluíram o ensino fundamental $(27,78 \%)$ e superior $(27,78 \%)$.

Todos os participantes foram orientados em relação aos objetivos da pesquisa e métodos de participação, além de preencherem o Termo de Consentimento Livre Esclarecido. Ressalta-se que, para dar início à coleta de dados do presente estudo, foi necessária a aprovação do Comitê de Ética em Pesquisa da nossa instituição, por meio da certidão de aprovação no protocolo de $n^{\circ} 665 / 10$ e folha de rosto $n^{\circ} 384581$.

Considerando os critérios de elegibilidade exibidos, foram inseridos no estudo seis idosos com hipótese diagnóstica de Doença de Alzheimer em fase inicial e 12 idosos sem patologias neurológicas, sendo seis institucionalizados e seis não institucionalizados. Diante das condições clínicas, comportamentais e de socialização, presentes em idosos de instituições de longa permanência, os experimentos foram aplicados com os dois grupos de idosos (institucionalizados e não institucionalizados). Mas, torna-se importante ressaltar, antecipadamente, que, independentemente de os idosos do grupo controle serem institucionalizados ou não, foram analisados conjuntamente, pois verificou-se que os tempos de resposta no experimento não demonstraram diferenças estatisticamente significativas.

\section{Instrumentos}

A pesquisa foi conduzida por meio de dois experimentos psicolinguísticos. O primeiro teve como objetivo comparar o processamento do pronome lexical com o do nome repetido em posição de objeto em Português Brasileiro, ambos com retomadas de antecedentes também na posição de objeto. Por meio deste experimento, buscou-se testar a hipótese de que pronomes em posições não proeminentes, como a de objeto direto em PB, mas na mesma posição e função sintática do antecedente (paralelismo estrutural), estabelecem de maneira natural e eficiente a correferência com um antecedente também em posição de objeto.

Com base em estudo realizado anteriormente no português brasileiro $^{(4)}$, no experimento atual, foram reaplicadas as suas frases experimentais, com o intuito de analisar o processamento correferencial em idosos com e sem a Doença de Alzheimer, nas condições de retomada de pronome (PR) e nome repetido (NR), na posição de objeto. Buscou-se aferir o tempo de retomada dos idosos com e sem DA, nas duas condições, com base nas variáveis independentes: grupo; tipo de retomada; e as variáveis dependentes: índice de acertos e tempo de leitura do segmento crítico.

O material consistiu de oito frases experimentais e 24 frases distratoras apresentadas a todos os participantes da pesquisa. 
O conjunto experimental foi composto por duas condições, uma com a retomada sendo o pronome (a) e outra com o nome repetido (b), conforme exemplificação apresentada abaixo.

a. Os detetives/ investigaram/Isa/ na Itália/mas/ não/ rastrearam/ ela/ no/ Japão.

b. Os detetives/ investigaram/Isa/ na Itália/mas/ não/ rastrearam/ Isa/ no/ Japão.

No segundo experimento, foi analisado o processamento da correferência estabelecida a partir de sintagmas nominais hiperônimos, e de sintagmas nominais hipônimos, em relação aos seus respectivos antecedentes, em posição de objeto direto. Buscou-se comprovar a hipótese de hiperônimos serem processados mais rapidamente do que os hipônimos em $\mathrm{PB}$, em idosos sem alterações neurológicas, como também comparar esses resultados com o desempenho obtido pelos idosos com Alzheimer.

As seguintes variáveis foram manipuladas: a independente foi o tipo de sintagma nominal utilizado na retomada anafórica (hipônimo ou hiperônimo); e as dependentes foram o tempo de leitura aferido após a apresentação das retomadas anafóricas (segmento oito), e o índice de acertos nas respostas às perguntas apresentadas no fim da leitura das frases. Foram lidas oito frases experimentais e 24 frases distratoras, também reaplicadas a partir de estudo anteriormente realizado em português ${ }^{(4)}$, randomizadas nas duas condições, uma com a retomada sendo hipônimo (c) e outra com o hiperônimo (d), conforme exposto a seguir.

c. Os biólogos/ avistaram/ um réptil/ no/ rio/ mas depois/ assustaram/ o jacaré/na/ margem.

d. Os biólogos/ avistaram/ um réptil/ no/ rio/ mas depois/ assustaram/ $\mathbf{o}$ animal/ na/ margem.

Nos dois experimentos, após a leitura fragmentada das frases experimentais, surgia uma pergunta final relacionada ao seu conteúdo, que permitia uma possível análise sobre o efetivo estabelecimento da correferência entre as retomadas e os antecedentes das frases.

P: c. Os biólogos avistaram o jacaré?

d. Os biólogos avistaram o animal?

\section{Procedimentos}

Inicialmente realizou-se o teste para a triagem cognitiva dos idosos voluntários, com o uso do teste MEEM de linguagem e memória. Após essa etapa, os participantes foram submetidos a dois experimentos on-line, utilizando o Programa Psyscope para plataforma Macintosh ${ }^{(24)}$ para a investigação dos processos cognitivos em ação na compreensão de palavras e frases. Nesse sentido, foram realizados experimentos psicolinguísticos com a técnica de leitura automonitorada.

A Técnica de Leitura Automonitorada, é uma técnica em que se fragmenta a frase em diversos segmentos e o participante deve controlar o seu próprio tempo de leitura de cada segmento que aparece na tela do computador, apertando as teclas indicadas, sendo esse tempo também registrado pelo próprio computador. Ao início de cada prática experimental, os idosos eram submetidos a um treinamento, utilizando frases que não constavam no experimento, para avaliar a compreensão dos idosos em relação à tarefa que deveria ser executada, como também para perceber a existência de alguma dificuldade que pudesse impossibilitar a participação na atividade. No estudo, o texto foi dividido em dez segmentos que foram apresentados, um por vez, em uma tela de computador; e o participante teria que apertar uma tecla para ler o segmento seguinte. A medida de principal interesse foi o tempo de leitura do segmento crítico da retomada anafórica (segmento oito), pois a partir desse tempo, pode-se avaliar os efeitos das variáveis independentes.

\section{Análise}

Para a interpretação dos dados, foi realizada uma análise estatística descritiva e inferencial, a fim de verificar as variáveis estudadas, fazendo uso de testes para a análise comparativa entre os grupos (idosos sem e com Alzheimer), considerando o tempo de leitura nas condições (nome repetido, pronome repetido, hiperônimo e hipônimo) e o índice de acertos das respostas às perguntas finais. A análise estatística foi realizada por meio dos pacotes estatísticos Statistical Package for Social Sciences (SPSS) 20.0 e Action 2.4, a normalidade dos dados foi confirmada por meio do Teste de Shapiro-Wilk, foram selecionados os testes ANOVA, Teste T e Qui-quadrado $\left(\mathrm{X}^{2}\right)$, considerando o nível de significância de $\mathrm{p}<0,05$.

\section{RESULTADOS}

A Figura 1 caracteriza as médias dos tempos de resposta, em milissegundos, com os quais os idosos do grupo controle (ISA) e os idosos do grupo experimental (IDA) realizaram a leitura do segmento crítico, nas condições experimentais com pronome (PR) ou com nome repetido (NR), mensuradas pela técnica de leitura automonitorada.

A análise estatística constatou, como significativo, um efeito principal de grupo [ANOVA $\mathrm{F}(3,68)=56,6 \mathrm{p}<0,00000$ ], e efeito de interação entre grupo e tipo de retomada [ANOVA

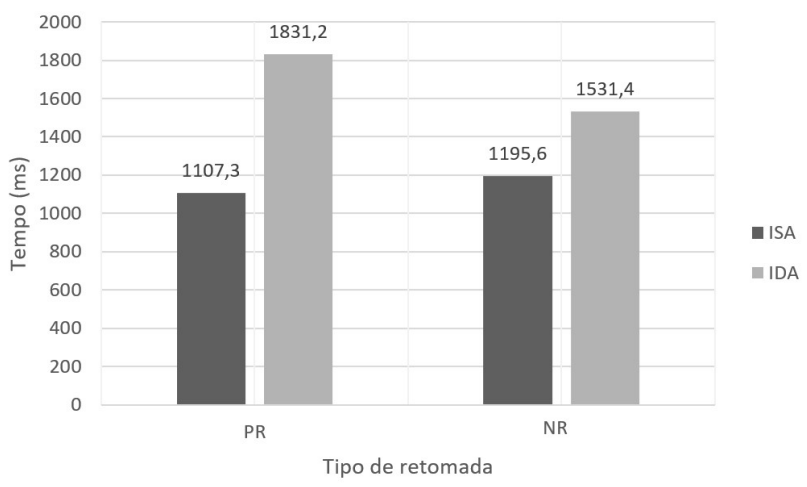

Legenda: ISA = Idosos sem Doença de Alzheimer; IDA = Idosos com Doença de Alzheimer; PR = Pronome Repetido; NR = Nome Repetido

Figura 1. Tempo de leitura da retomada anafórica dos idosos com e sem a Doença de Alzheimer no experimento 1 
$\mathrm{F}(3,68)=22,37 \mathrm{p}<0,00000]$. Por outro lado, não houve efeito principal de tipo de retomada [ANOVA $\mathrm{F}(3,68)=0,07 \mathrm{p}=0,78]$.

Para observar se houve efeito do tipo de retomada pelos grupos testados, realizou-se uma análise estatística de cada grupo isoladamente. Com base nessa análise, o grupo controle demonstrou uma diferença significativa das médias das condições PR e NR, em que o tempo de leitura das retomadas com pronomes foi mais rápido do que na retomada de nomes repetidos, como pode-se observar no Teste $\mathrm{T}[\mathrm{T}(11)=3,36$ $\mathrm{p}<0,002]$.

Já no grupo experimental de idosos com DA (IDA), ao contrário do grupo controle, os tempos de leitura da retomada com nome repetido foi significativamente mais rápido que os tempos de leitura da retomada com pronomes, Teste $\mathrm{T}[\mathrm{T}(5)=2,139$ $\mathrm{p}=0,0381]$.

A Tabela 1 demonstra o número de acertos e erros à resposta final das frases experimentais, que objetivam confirmar se os indivíduos realizaram a correferência durante a leitura das frases experimentais, que apresentavam pronome ou nome repetido no segmento crítico. É importante ressaltar que o valor absoluto do número de respostas torna-se diferente por se ter um grupo controle com o dobro de indivíduos em relação ao grupo experimental.

Na análise estatística, com aplicação do teste de Qui-quadrado, foi constatado que não houve significância no índice de respostas da variável grupo $\left(\mathrm{X}^{2}=0,016 \mathrm{p}=0,9\right)$. Diante dos números de acertos e erros apresentados pelos grupos pesquisados, podese perceber que independente da presença ou não do quadro clínico neurológico (DA), os voluntários demonstraram um bom desempenho nas respostas, o que demonstra que, provavelmente, os idosos realizaram a correferência, mesmo com tempos de leitura diferentes entre as condições PR e NR. Assim como no MEEM, a tarefa off-line captou um bom desempenho dos idosos com e sem a DA, em atividades que envolvem os aspectos linguísticos. Mas isso não ocorreu com atividades que envolveram os aspectos cognitivos.

Os idosos com Doença de Alzheimer apresentaram um maior comprometimento no domínio relativo à memória de trabalho no MEEM, quando comparados aos sem patologia. No exame foi observado um efeito significativo entre os grupos em todos os itens associados aos aspectos cognitivos, incluindo o componente memória de trabalho avaliado por meio das provas de memória imediata [ANOVA $F(0,08)=21,3 p<0,01$ ], com menores médias encontradas no grupo $\operatorname{IDA}(2,3)$ em comparação ao grupo ISA $(3,0)$.

Em relação ao experimento 2, a análise das médias de tempo registradas do segmento crítico, nas condições experimentais do tipo de retomada (hipônimo ou hiperônimo) é apresentada

Tabela 1. Respostas das perguntas interpretativas dos idosos sem e com a Doença de Alzheimer no experimento 1

\begin{tabular}{clcc}
\hline RESPOSTA & GRUPO ISA & GRUPO IDA & P-valor \\
\hline Acertos & $95(98,96 \%)$ & $41(85,42 \%)$ & $\mathbf{p}=\mathbf{0 , 9}$ \\
Erros & $01(1,04 \%)$ & $07(14,58 \%)$ & \\
Total & $96(100 \%)$ & $48(100 \%)$ & \\
\hline
\end{tabular}

Comparações intergrupos, teste Qui-quadrado; $p<0,05$

Legenda: ISA = Idosos sem Doença de Alzheimer; IDA = Idosos com Doença de Alzheimer na Figura 2. O resultado significativo encontrado foi um efeito principal de grupo [ANOVA $F(3,68)=25,09 \mathrm{p}<0.05$ ], não havendo efeito principal de retomada $[\operatorname{ANOVA~} \mathrm{F}(3,68)=1,75$ $\mathrm{p}<0,18]$, nem efeito de interação entre a variável grupo e tipo de retomada [ANOVA $F(3,68)=0,19 \mathrm{p}<0,65]$.

No entanto, também na Figura 2, ao analisar isoladamente cada grupo investigado, observa-se que a diferença das médias dos tempos de leitura das condições HPO e HPE, nos voluntários do grupo controle (ISA), foram na direção esperada, ou seja, quando a retomada era um substantivo superordenado (hiperônimo) em relação ao antecedente, os tempos de leitura foram significativamente menores que os tempos de leitura com a retomada via hipônimo, demonstrando, assim, que hiperônimos são lidos mais rapidamente do que hipônimos no estabelecimento da correferência, Teste T [T(11) $=2,0786 \mathrm{p}<0,05]$.

Os tempos de leitura das condições HPE e HPO, registrados nos idosos com DA, ao contrário do grupo controle, não obtiveram diferença significativa no desempenho do tempo de retomada entre HPO e HPE, segundo dados obtidos pelo Teste T [T(5) = $0,341 \mathrm{p}<0,43]$. Os idosos com DA, além de apresentarem uma média de tempo de retomada alta, não se mostraram sensíveis a nenhuma das condições.

A Tabela 2 apresenta o índice de acertos e erros nas respostas às perguntas finais que surgem após as frases experimentais. Objetiva-se, com a mesma, confirmar se os indivíduos realizaram ou não a correferência durante a leitura das frases testadas que, nesse experimento, apresentaram a retomada anafórica com hipônimos e hiperônimos. Como também, essa análise permite uma percepção da participação

Tabela 2. Respostas das perguntas interpretativas dos idosos sem e com a Doença de Alzheimer no experimento 2

\begin{tabular}{cccc}
\hline RESPOSTA & GRUPO ISA & GRUPO IDA & P-valor \\
\hline Acertos & $72(75 \%)$ & $34(70,83 \%)$ & $\mathbf{p}=\mathbf{0 , 4}$ \\
Erros & $24(25 \%)$ & $14(29,17 \%)$ & \\
Total & $96(100 \%)$ & $48(100 \%)$ & \\
\hline
\end{tabular}

Comparações intergrupos, teste Qui-quadrado; $p<0,05$

Legenda: ISA = Idosos sem Doença de Alzheimer; IDA = Idosos com Doença de Alzheimer

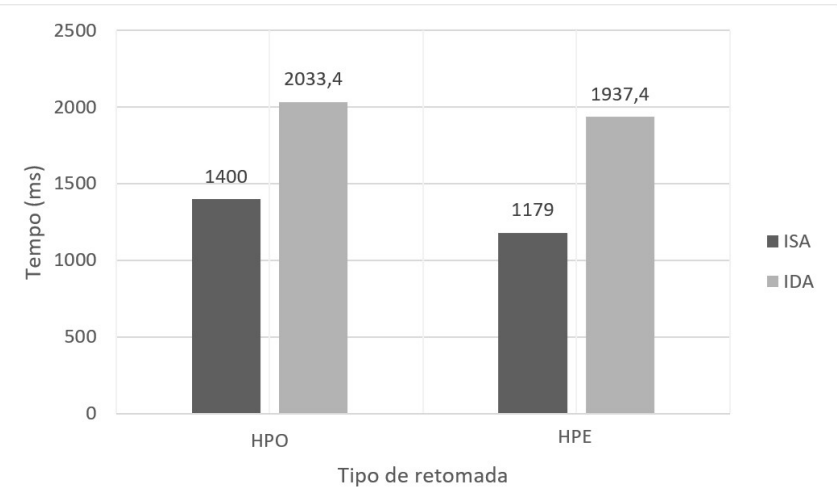

Legenda: ISA = Idosos sem Doença de Alzheimer; IDA = Idosos com Doença de Alzheimer; HPO = Hipônimo; HPE = Hiperônimo

Figura 2. Tempo de leitura da retomada anafórica dos idosos com e sem a Doença de Alzheimer no experimento 2 
dos aspectos semânticos, na interpretação da frase e na relação com a retomada anafórica.

Na análise estatística do teste de Qui-quadrado, constatouse que não houve efeito significativo no índice de respostas da variável grupo $\left(\mathrm{X}^{2}=0,67 \mathrm{p}=0,4\right)$. Os achados experimentais caracterizaram que independente do correferencial ser hiperônimo ou ser hipônimo, os participantes com DA, ao lerem as frases experimentais, não demonstraram preferência por nenhumas das condições.

\section{DISCUSSÃO}

Nesta pesquisa, partindo dos resultados do primeiro experimento, considerando os valores do tempo de leitura da retomada anafórica do grupo controle, assim como em outros estudos, foi constatada a Penalidade do Nome Repetido, como previsto pela teoria da centralização ${ }^{(6)}$, que tem como um de seus princípios a eficiência dos pronomes no estabelecimento da correferencialidade. O mesmo critério de análise não se aplica ao que foi demonstrado pelos idosos com DA, diferentemente do grupo controle, esses idosos tiveram mais rapidez na retomada do nome repetido do que na retomada do pronome, podendo ser decorrente das alterações na memória de trabalho, como afirmam estudos ao analisar indivíduos com $\mathrm{DA}^{(5)}$ e crianças com Transtorno do Déficit de Atenção e Hiperatividade - TDAH ${ }^{(25)}$. Os autores argumentam que essas diferenças significativas na retomada anafórica, em que os sujeitos processam mais rapidamente, durante a leitura, o nome repetido do que o pronome, são resultantes do prejuízo na memória de trabalho.

O presente estudo corrobora com os achados em diversas pesquisas nacionais que utilizaram metodologia semelhante ${ }^{(3,13,14)}$, uma vez que os idosos do grupo controle apresentaram maior rapidez nos tempos de leitura das retomadas dos antecedentes com pronomes lexicais, quando comparados às médias dos tempos de leitura das retomadas dos antecedentes com nomes repetidos. Assim, constatou-se que nos idosos sem alterações da linguagem, ocorre a Penalidade do Nome Repetido na posição de objeto e não apenas na posição de sujeito, contrapondo a Teoria da Centralização, e que retomadas anafóricas são processadas mais rapidamente do que seus antecedentes, mesmo não estando em foco, ao contrário do indicado pela Hipótese da Carga Informacional e em conformidade aos resultados encontrados em outra pesquisa realizada anteriormente no Português Brasileiro ${ }^{(4)}$.

Divergindo dos resultados encontrados no grupo controle, a compreensão de pronomes em idosos com a DA está comprometida pelo decréscimo na ativação do referente na memória de trabalho, passando esses indivíduos a serem mais eficientes no estabelecimento da correferência com os nomes repetidos. Ao assumir a influência direta da memória de trabalho nessa inversão do padrão de processamento da retomada anafórica, corroborase com as pesquisas ${ }^{(5,25)}$ que captaram uma maior velocidade no tempo de leitura, da retomada anafórica do nome repetido do que no pronome, nos idosos com DA (com o Inglês como primeira língua) e nas crianças com TDAH, respectivamente. Nessas duas patologias existem registros de dificuldades na memória de trabalho, conforme já foi exposto.
No processo natural de envelhecimento, existe uma relativa preservação do vocabulário e do processamento sintático, mas podem surgir alterações na lembrança, sendo presente no diálogo cotidiano o uso de estratégias comunicativas relacionadas à adequação pragmática da situação. Contudo, vale ressaltar que tais estratégias se relacionam às dificuldades de acesso ao léxico, bem como às dificuldades em outros componentes cognitivos, sejam eles os diferentes tipos de memória, a atenção e as funções executivas. Essas mesmas características são observadas com graus mais acentuados nos indivíduos com Doença de Alzheimer e Comprometimento Cognitivo Leve, especialmente a hesitação e o circunlóquio, podendo-se argumentar uma relação direta desse comprometimento semântico e discursivo com a memória de trabalho ${ }^{(26)}$.

Neurofisiologiamente podemos esperar a influência da semântica deteriorada alterar a memória de trabalho, ou no processo inverso, que a Doença de Alzheimer, ao desencadear alterações na memória de trabalho, pode interferir nos aspectos semânticos dos sujeitos acometidos. Nos resultados do presente estudo, com um alto valor no número de acertos às perguntas finais, foram encontradas possíveis evidências de que o sistema semântico está preservado, pelo menos, na fase inicial da doença. Por outro lado, como já mencionado, os idosos com DA apresentaram tempos mais rápidos de leitura para a retomada com nomes repetidos, do que com os pronomes, ou seja, os nomes repetidos facilitaram o processamento correferencial, o que é inverso ao que ocorre com o grupo controle.

Em ambos os casos, assim como evidenciado via teste de memória contido no MEEM, nos indivíduos com DA pesquisados, há indícios de que, por conta do comprometimento na memória de trabalho, esses idosos tenham maior facilidade de ativar os antecedentes relacionados às respectivas retomadas anafóricas quando estas são nomes repetidos, já que diferentemente dos pronomes, os nomes conseguem reativar todos os traços referentes aos antecedentes.

Os resultados do experimento 2, apresentados pelos idosos do grupo controle, confirmam a Hipótese da Carga Informacional, que identifica o fenômeno no momento em que as retomada anafóricas menos explícitas evocam uma representação conceptual mais geral e menos específica do referente, o que representa a preferência dos voluntários sem patologia pelos hiperônimos, pois os hipônimos que têm maior carga informacional dificultam o estabelecimento da correferência, e, algumas vezes, parecem ser interpretados como uma nova entidade discursiva.

Assim como nas pesquisas em inglês ${ }^{(7)}$, e em Português Brasileiro $^{(3,13)}$, ao investigarem sujeitos sem alterações neurológicas, os atuais resultados experimentais também registraram diferenças significativas nas médias dos tempos de leitura das retomadas dos antecedentes com hiperônimos, quando comparadas às médias dos tempos de leitura das retomadas dos antecedentes com hipônimos.

No caso dos idosos com DA, além de demorarem mais para desencadear a retomada anafórica, não apresentaram diferença estatisticamente significativa entre as duas condições (HPO e HPE). Em relação a esses indivíduos, é comprovado que a linguagem sofre uma influência direta do declínio progressivo das capacidades intelectuais em decorrência da doença, se 
estendendo além do domínio semântico-lexical, que se acredita ser resultante das alterações na memória de trabalho.

Diante do exposto, acreditamos que na fase inicial da Doença de Alzheimer, o comprometimento seja iniciado na memória de trabalho e que essa por sua vez irá interferir no sistema semântico, nas fases seguintes da doença degenerativa. Buscou-se evidência dessa predição, ao serem analisadas as respostas das frases finais (processamento offline) deste experimento, pelo índice de acertos que foram apresentadas pelos idosos com DA.

Com o número de acertos e erros apresentados pelos grupos pesquisados, percebe-se que independente da presença ou não da Doença de Alzheimer, os idosos tiveram um bom desempenho nas respostas (offline), caracterizando que houve o estabelecimento da correferência entre retomada e antecedente, nesta etapa, mesmo havendo diferenças entre as condições PR e NR em termos de tempo de leitura.

Referente ao número de acertos e erros nas respostas do segundo experimento, os números indicaram que independente do correferencial ser hiperônimo ou ser hipônimo, ao participarem da atividade offline, os idosos estabeleceram a correferência com o antecedente disponível. É importante enfatizar que os índices de resposta dos idosos com a Doença de Alzheimer (na fase inicial da doença) não tiveram diferença significativa quando comparados aos idosos do grupo controle, ou seja, não mostraram prejuízos em compreender as relações semânticas necessárias para o estabelecimento da correferência, diferente do que ocorreu no processamento online aferido via tempo de leitura da retomada.

Por fim, não foram encontradas diferenças significativas entre as médias nos tempos de leitura das condições de hipônimo e hiperônimo dos idosos com DA. Diante de todos os resultados apresentados, pode-se assumir que indivíduos com Doença de Alzheimer, na fase inicial, não apresentam comprometimento nos aspectos do sistema semântico e sim na memória de trabalho. Por ser a Doença de Alzheimer uma patologia degenerativa, esse comprometimento na memória de trabalho tende a se agravar e consequentemente a aumentar a disfunção do sistema semântico.

Entende-se que a ausência de diferença significativa entre as condições experimentais (HPO e HPE) na retomada anafórica seja decorrente do comprometimento na memória de trabalho. Nesses casos, os idosos com Doença de Alzheimer podem necessitar de mais tempo para conseguirem processar e relacionar os traços semânticos capazes de reativar os respectivos antecedentes, tanto via hipônimo, quanto via hiperônimo, diferentemente do que ocorreu nos resultados entre pronomes e nomes repetidos, pois os nomes repetidos promovem sem nenhum custo adicional a reativação de todos os traços correspondentes aos respectivos antecedentes.

Nesse sentido, cabe aqui apresentar os resultados de um estudo longitudinal que considerou aspectos da linguagem para identificar um marcador precoce da DA. A recuperação lexical foi investigada em três testes de linguagem (nomeação, fluência verbal e descrição escrita) com comparações envolvendo participantes com DA e indivíduos saudáveis. Os resultados indicaram que o grupo com Alzheimer apresentou declínio progressivamente maior no desempenho lexical e que os déficits de recuperação lexical no discurso escrito servem como um indicador precoce, diferenciando o desempenho entre os dois grupos entre 7 e 9 anos antes da morte dos indivíduos ${ }^{(27)}$.

Os autores sugerem que a atenção prejudicada, as funções executivas e a memória de trabalho podem influenciar na recuperação de palavras na DA. Sendo que, a memória de trabalho exerce um papel crucial, pois fornece armazenamento e processamento temporários de informações necessárias para executar com êxito as tarefas, permitindo uma busca sistemática e eficaz por palavras, flexibilidade para alterar uma estratégia de busca quando necessário, assim como o monitoramento dos processos de recuperação lexical ${ }^{(27)}$. Ou seja, as dificuldades apresentadas por esses indivíduos se relacionam aos déficits de memória existentes, que prejudicam o acesso ao léxico e a retenção de informações na memória durante a execução de tarefas, e não puramente a uma dificuldade de ordem semântica.

Com base nos suportes teóricos descritos e nos dados explicitados, procurou-se também subsidiar a área clínica da linguagem, sugerindo estratégias de intervenção fonoaudiológica. A primeira delas, é que nos testes de avaliação da linguagem e cognição possa ser inserida uma atividade online com o uso de anáforas e antecedentes, em que os indivíduos que demonstrarem melhor desempenho na retomada com pronome do que com o nome repetido poderão não ter comprometimento da memória de trabalho. Por outro lado, os que apresentarem preferência pelo nome repetido podem caracterizar tendências de alterações nesse aspecto.

A segunda seria a relação dos resultados da primeira atividade com uma atividade de avaliação semântica (de compreensão de sentenças curtas, por exemplo), se os sujeitos apresentassem, além da preferência pelo nome repetido, baixo desempenho semântico, isso poderia ser característico de uma fase mais avançada do Alzheimer, uma vez que indivíduos com a DA na fase leve, tenderiam a não demonstrar alterações semânticas de base.

A terceira sugestão seria inserir no planejamento terapêutico fonoaudiológico, sessões clínicas dedicadas à aplicação de frases com anáforas e antecedentes com nome repetido para estimular a velocidade do processamento, uma vez que a retomada do nome repetido é mais acessível para essa população com DA.

Por fim, na fase inicial da Doença de Alzheimer, fazer uso de atividades que usem o nível semântico, que estimulem esse campo que ainda parece estar preservado, para que os indivíduos com DA venham a desenvolver um maior tempo funcional de linguagem e uma melhor qualidade de vida. A partir desses aspectos, o fonoaudiólogo também pode oferecer orientações aos cuidadores, visando facilitar o convívio familiar e social desses indivíduos.

Vale salientar que na prática clínica não se concluem diagnósticos com base em um ou dois sinais e sintomas clínicos, mas sim com um conjunto de fatores. Diante das atividades anteriormente propostas, os resultados adquiridos em suas aplicações serão somados com outros fatores para determinar os achados clínicos, e fechar as hipóteses e adequações dos procedimentos terapêuticos mais favoráveis. No presente estudo, uma limitação foi a não realização de uma avaliação cognitiva mais ampla dos participantes, com dados mais substanciais que pudessem auxiliar na discussão das concepções aqui levantadas. 


\section{CONCLUSÃO}

Os idosos com diagnóstico de Doença de Alzheimer em sua fase inicial apresentaram resultado inverso ao dos idosos sem alterações neurológicas, demonstrando mais rapidez na retomada de nomes repetidos do que de pronomes, o que permite a confirmação da hipótese do comprometimento da memória de trabalho, comum em idosos com DA. Somente nos idosos sem patologias neurológicas foi confirmada a assunção básica da teoria da Hipótese da Carga Informacional em relação a retomadas mais explícitas que evocam uma representação conceptual mais geral e menos específica do referente, preferindo o estabelecimento da correferência com pronomes e hiperônimos. Em ambos os grupos, houve um bom nível de acerto das perguntas finais, indicando uma satisfatória compreensão e menores prejuízos associados ao domínio semântico no processamento da correferência.

\section{REFERÊNCIAS}

1. Scheltens P, Blennow K, Breteler MMB, Strooper B, Frisoni GB, Salloway S, et al. Alzheimer's disease. Lancet. 2016;388(10043):505-17. http:// dx.doi.org/10.1016/S0140-6736(15)01124-1. PMid:26921134.

2. Kirova AM, Bays RB, Lagalwar S. Working memory and executive function decline across normal aging, mild cognitive impairment, and Alzheimer's Disease. BioMed Res Int. 2015;2015:748212. http://dx.doi. org/10.1155/2015/748212. PMid:26550575.

3. Szatloczki G, Hoffmann I, Vincze V, Kalman J, Pakaski M. Speaking in Alzheimer's disease, is that an early sign? Importance of changes in language abilities in Alzheimer's disease. Front Aging Neurosci. 2015;7:195. http:// dx.doi.org/10.3389/fnagi.2015.00195. PMid:26539107.

4. Leitão MM. Processamento co-referencial de nomes e pronomes em português brasileiro. Lingüística. 2005;1(2):235-58.

5. Almor A, Kempler D, Macdonald M, Andersen E, Tyler L. Why do Alzheimer patients have difficulty with pronouns? Working memory, semantics, and reference in comprehension and production in Alzheimer's Disease. Brain Lang. 1999;67(3):202-27. http://dx.doi.org/10.1006/brln.1999.2055. PMid:10210631.

6. Gordon PC, Chan D. Pronouns, passives and discourse coherence. J Mem Lang. 1995;34(2):216-31. http://dx.doi.org/10.1006/jmla.1995.1010.

7. Almor A. Noun-phrase anaphora and focus: the informational load hypothesis. Psychol Rev. 1999;106(4):748-65. http://dx.doi.org/10.1037/0033295X.106.4.748. PMid:10560327.

8. Gordon PC, Grosz BJ, Gilliom LA. Pronouns, names, and the centering of attention in discourse. Cogn Sci. 1993;17(3):311-47. http://dx.doi. org/10.1207/s15516709cog1703_1.

9. Kennison SM, Gordon PC. Comprehending referential expressions during reading: evidence from eye tracking. Discourse Process. 1997;24(2-3):22952. http://dx.doi.org/10.1080/01638539709545014.

10. Chambers C, Smyth R. Structural parallelism and discourse coherence: a test of centering theory. J Mem Lang. 1998;39(4):593-608. http://dx.doi. org/10.1006/jmla.1998.2575.

11. Yang CL, Gordon PC, Hendrick R, Wu JT. Comprehension of referring expressions in Chinese. Lang Cogn Process. 1999;14(5-6):715-43. http:// dx.doi.org/10.1080/016909699386248.
12. Ernst E. Le traitement en temps réel de l'anaphore pronominale dans le langage écrit. Développement normal et dysfonctionnements. Apports de la théorie du Centrage [thèse]. Paris: Université Paris V; 2007.

13. Queiroz K, Leitão MM. Processamento do sujeito anafórico em português brasileiro. Veredas. 2008;12(2):163-6.

14. Leitão MM, Simões ABG. A influência da distância no processamento correferencial de pronomes e nomes repetidos em português brasileiro. Veredas. 2011;7(1):198-224.

15. Leitão MM, Ribeiro AJC, Maia M. Penalidade do nome repetido e rastreamento ocular em português brasileiro. Revista LinguíStica. 2012;8(2):35-55.

16. Lima JC. Paralelismo e foco estrutural no processamento da correferência de pronomes e nomes repetidos [dissertação]. João Pessoa: Universidade Federal da Paraíba; 2014.

17. Maia JC, Lima MLC. O processamento de expressões correferenciais em português brasileiro: nomes repetidos, pronomes plenos e pronomes nulos. Revista do GELNE. 2011;13(1-2):1-15.

18. Maia JC, Lima MLC. Processamento correferencial de nomes e pronomes plenos em PB: evidências de rastreamento ocular. ReVEL. 2012;10(6):11030 .

19. Maia JC, Lima MLC. Referenciação e técnicas experimentais: aspectos metodológicos na investigação do processamento correferencial em português brasileiro. Revista de Estudos da Linguagem. 2014;22(1):67-93 . http://dx.doi.org/10.17851/2237-2083.22.1.67-93.

20. Almor A, Maia JC, Lima MLC, Vernice M, Gelormini-Lezama C. Language processing, acceptability, and statistical distribution: a study of null and overt subjects in Brazilian Portuguese. J Mem Lang. 2017;92:98-113. http://dx.doi.org/10.1016/j.jml.2016.06.001.

21. Gondim EVAC. Investigação teórico-metodológica sobre penalidade do nome repetido em português brasileiro [dissertação]. João Pessoa: Universidade Federal da Paraíba; 2017.

22. Bertolucci PHF, Brucki SMD, Campacci SR, Juliano Y. The Mini-Mental State Examination in an outpatient population: influence of literacy. Arq Neuropsiquiatr. 1994;52(1):1-7. http://dx.doi.org/10.1590/S0004282X1994000100001.

23. Lourenço RA, Veras RP. Mini Exame do Estado Mental: características psicométricas em idosos ambulatoriais. Rev Saude Publica. 2006;40(4):7129. http://dx.doi.org/10.1590/S0034-89102006000500023. PMid:16906312.

24. Cohen JD, MacWhinney B, Flatt M, Provost S. Psyscope: a new graphic interactive enviroment for designing psychology experiments. Behav Res Methods. 1993;25(2):257-71. http://dx.doi.org/10.3758/BF03204507.

25. Albuquerque GS, Maia M, França A, Mattos P, Pastura G. Processamento da linguagem no transtorno do déficit de atenção e hiperatividade. Delta. 2012;28(2):245-80. http://dx.doi.org/10.1590/S0102-44502012000200003.

26. Jerônimo GM. Envelhecimento sadio, Comprometimento Cognitivo Leve e doença de Alzheimer: um estudo das estratégias comunicativas na narrativa oral. Let Hoje. 2018;53(1):177-86. http://dx.doi.org/10.15448/19847726.2018.1.28894.

27. Pekkala S, Wiener D, Himali JJ, Beiser AS, Obler LK, Liu Y, et al. Lexical retrieval in discourse: an early indicator of Alzheimer's dementia. Clin Linguist Phon. 2013;27(12):905-21. http://dx.doi.org/10.3109/02699206 .2013.815278. PMid:23985011.

\section{Contribuição dos autores}

GÂSA foi responsável pela concepção e delineamento do estudo; aquisição, análise e interpretação dos dados; além da redação do artigo; JFC foi responsável pela revisão crítica final da versão a ser apresentada para publicação; $M M L$ foi responsável pela revisão crítica de informações intelectuais relevantes e orientação da pesquisa. 